\title{
A Decade of Changes in University Website Design
}

\author{
Marzie Astani, Winona State University, mastani@winona.edu
}

\begin{abstract}
Many organizations are engaged in e-commerce using the Internet in addition to the brick and mortar methods of doing business. To this end, firms are engaged in designing functionally sound and effective websites to attract customers. Customizing organization's website is used as a tool for interacting and providing information for customers and business partners. Universities and colleges have been using their websites as a student recruiting means. An effective website design is very important for higher education institutions to attract students. This research explores the effectiveness of the university websites from students' perspectives. The findings of this study are compared to a study conducted ten years ago. Some recommendations are made based on the findings.
\end{abstract}

Key Words: University websites, design attributes, target audience, customer-centric

\section{INTRODUCTION}

The growth of e-commerce has been the driving force for studies investigating the determinants of an effective business website and how they can be measured. Several research studies have investigated the attributes of a good business website design $[5,16,17,24,25,29]$. Unfortunately, non-business organizations have been generally neglected in this process. Among the few studies focusing on non-business organizations is Ceaparu and Shneiderman's research focusing on state government websites [5]. The authors made several recommendations to improve information delivery and effectiveness of websites. Higher education institutions are among the nonbusiness organizations that need to be concerned about their website design and functionality. Just recently higher education institutions have started to pay attention to their websites' design effectiveness and view them as a recruiting tool to attract students. But clearly there is a lack of sufficient studies investigating university websites design effectiveness.

Whether an organization is a business or non-business, all experts agree that its website needs to be customer-centric $[12,16,17]$. This means that the website must be designed to meet the needs of a target audience. However, a number of factors play crucial roles in developing a good website. Having an inviting website that is easy to navigate and provides necessary information is vital to any organization. Web surfers have high expectations regardless of whether they are online for work or personal reasons. As a result, an organization, whether it is a business company or an educational institution, needs to be very careful about the image that is projected through its website. The educational institutions know that parents and high school students use the Internet as an initial tool to shop around for the best college. A major concern of these educational institutions should be whether their websites are projecting their schools effectively. The goal of these organizations should be to effectively present their academic offerings and opportunities through their websites.

No empirical study has been done to substantiate whether university websites are effective. The focus of this study is to explore the effectiveness of universities' websites based on characteristics that have been identified in the literature. The research question is whether university/college website designs are effective in attracting the target audience and effectively presenting relevant information. Ultimately, colleges and universities can improve their websites and increase recruitment of prospective students. Therefore, the objective of this research project is to collect information from students on university websites and analyze them to develop an understanding of the target audience's perspective and help colleges and universities in their recruiting efforts. The websites of 72 colleges and universities were rated and the results are analyzed. Then the results of this study were compared to a similar research done ten years ago to determine any changes. Finally, some insights are provided about university 


\section{Issues in Information Systems \\ Volume 14, Issue 1, pp.189-196, 2013}

websites' effectiveness. The research objective is to help educational institutions to achieve their goals by designing effective websites.

Next the literature review is presented, followed by the research methodology. Finally, the research results and conclusions/recommendations are presented.

\section{LITERATURE REVIEW}

In the early years of web presence, educational institutions' goal was to simply have a website. Now, many colleges and universities are attempting to include a strong content combined with information about the school and its educational resources [27]. According to studies of website design [15, 10], there are two parts in planning a website: 1) determine the goals and resources needed to achieve them, and 2) specify the target audience, site details, technology needed, and an assessment of the results. Thus, first, developers need to determine what the organization wants to accomplish on the web. For example, does it want to increase student recruitment or provide a teaching resource for lectures? Next, they must think about the audience and their requirements. The process of designing a website involves an iterative progression from less detailed to more detailed representations of the site. For example, designers often create site maps early in the process, which are high-level representations of a site in which each page or set of pages is depicted as a label [15].

A university website has two types of audiences. The primary audience is academic, general staff and students. The secondary audience is the general public and other educational institutions [19]. Although a well-designed website should accommodate a range of users' skills and interests, the key to a successful website is to understand the target audience and meet their needs. Ironically, those very users are the people least likely to be present and involved when the site is designed and built.

According to Steele [23], there is ample evidence to suggest that more and more educational institutions are using the Internet as a tool to recruit students. Regrettably, higher education institutions have failed to meet prospective students' college search requirements; rather their websites are geared for the campus community. Steele concludes that colleges have been passive sources of information and need to increase their communication with potential future students. He explains that, currently, students must go through many pages of information to find what the school has to offer. The importance of this issue is emphasized by the statistics showing that a typical student will not spend much time on a website if he/she doesn't find the information quickly. Each month, 17.3 million children and teens use the Internet and spend only 8 seconds viewing a website to determine whether it contains what they are interested in [23].

Many organizations are trying to design a website that would be attractive to the viewers. Building a website is not a one-time project with static content, rather an ongoing process which needs long-term editorial and technical management [10]. But the difficulty is that many website designers have little Knowledge of user interface design and usability engineering, therefore, wasting users' time and causing unnecessary traffic on the Internet.

Today's students are media savvy and have adapted to the current media-saturated environment by learning how to scan through massive amounts of information quickly and filter the ones they are searching for. In a marketing research done on behalf of various colleges and universities, 15,000 college-bound high school students were surveyed [23]. The results showed a clear trend of increasing usage of the Internet among this segment of the population, which was not unexpected. However, the interesting conclusion was that the higher achieving students use the Internet more than their peers to search for a college. Over $75 \%$ of all students indicated that college sites either "greatly increased" or "somewhat increased" their interests. 


\section{Issues in Information Systems}

\section{RESEARCH METHODOLOGY}

In their research, Tarafdar and Zhang [24] identified successful websites characteristics as: information content, navigation, usability, customization, download speed, and security. Other researchers have identified several attributes for website design [19,11]. However, several researchers such as Kaplan and Kaplan [10] focused on how people use information to satisfy their needs of making sense and exploring in an uncertain world in their Preference Framework. One way in which humans cope with processing information, they said, is through the use of cognitive maps. Using a cognitive or mental map provides us with a means of sorting and storing info from our environment. Cognitive maps are an accumulation or summary of experiences. Humans draw on these maps to make their way through an environment. These maps influence "how the environment 'feels' to that person, what is noticed, what is ignored" [10]. Having a cognitive map, however, is not enough. Humans must be motivated to use and extend these maps through environments designed to take advantage of these cognitive maps. People appreciate and are motivated to use info, which helps them expand previous knowledge contained in their cognitive maps.

Overall, for practitioners, the implication is what many site designers have tried to articulate: make it simple [20]. Adopting a minimalistic approach to the design of the home page with eye-catching but appropriate graphics and categories that draw the web surfer further into the site appears to be more effective. Web design should not result in info overload. The goal, rather, should be to give access to the info web surfers' desire in the most expedient way possible. Simplicity of design should be a major consideration as it not only makes the site more appealing, it also makes it far faster to load. Web surfers are not a patient group. Some web design experts have estimated that they have exactly 10 seconds to lure people into a site. It is not, therefore, surprising that slow loading sites are a major frustration and turnoff for web surfers. Another prerequisite is to make the website distinctive. A website with a distinct identity will appeal to web-weary surfers, differentiate the company and make the site more memorable. What must be determined is how much flexibility must be built into website content to satisfy the increasing diversity of users. At the same time, there are commonalities between experts and casual users. It is evident from the students' comments that even light users of the web can equate content quality, ease of use, etc. with design and typo-graphic factors.

The focus of this research study was the target audience's perception (mainly students) of "a good university website." That is whether the higher education institutions' websites are customer-centric from current students' perspectives. To determine this, a sample of 27 students in their second and third year of college were involved as subjects in this study and evaluated 72 randomly selected university websites. Students first read different articles about design attributes of websites. After reviewing the literature, they were asked to propose features that they thought should be on a university website. Eventually, the check list that was developed by Raward [19] was selected (with some modification) as the instrument for this study because it seemed to be the most relevant and was based on credible previous studies. Students rated the website design attributes based on a 5-point Likert Scale. The website evaluation was done independently by each student and completed over the course of three weeks.

\section{RESULTS AND DISCUSSIONS}

The final list of features which constituted the final instrument for evaluating the university websites is shown in Table 1. The final instrument consisted of 68 website attributes that were organized under four categories: 1) Finding the information, 2) Understanding the information, 3) Supporting user tasks, and 4) Presenting the information. There were 13 subcategories among the 4 major categories. The average ratings for these subcategories of website characteristic are shown in Table 2. It is evident that the universities have been making efforts to design good websites to attract students. 
An important characteristic of a website is content. Experts believe that it is the content that brings users to a website [8]. They suggest that a more valuable, dynamic, and updated content can attract more viewers. Researchers agree that the content should be easy to read and comprehend, relevant to the purpose of the website, and adequately in-depth $[4,11,13]$.

Table 1. University web site design attributes

\begin{tabular}{|c|c|}
\hline $\begin{array}{l}\text { A. FINDING THE INFORMATION } \\
\text { Content } \\
\text { 1. University logo is on each page. } \\
\text { 2. Staff contact for the page is included. } \\
\text { 3. It is possible to get feedback and ask questions. } \\
\text { 4. Phone, fax, email, and postal address are included on } \\
\text { each page. } \\
\text { 5. It is possible to get help. } \\
\text { 6. Services are clearly stated. } \\
\text { 7. Purpose statement provided. } \\
\text { 8. Acronyms are avoided where possible. } \\
\text { 9. Capitalization, spelling, and punctuation are correct. } \\
\text { Index } \\
\text { 10. Index is included. } \\
\text { 11. Entries are in alphabetical order. } \\
\text { 12. Second and third level entries included. } \\
\text { Site Map } \\
\text { 13. Site map is included. } \\
\text { 14. Links to site map are correct. } \\
\text { Headings (Choose one page at random) } \\
\text { 15. Headings within page are labeled correctly. } \\
\text { 16. Headings are brief and informative. } \\
\text { 17. Headings stand out on the page. } \\
\text { 18. At least one heading exist on every page. } \\
\text { 19. Headings accurately reflect task or information. } \\
\text { Search (Choose a topic for your search) } \\
\text { 20. A search tool is included on the site. } \\
\text { 21. The topic was easy to find. } \\
\text { 22. A user can find an answer within } 10 \text { seconds. } \\
\text { Currency and Accuracy of Information } \\
\text { 23. The date of the last updated is included. } \\
\text { 24. The last updated date is on every page. } \\
\text { 25. The new information is indicated on the page. } \\
\text { 26. There is "What's New" page on the site. } \\
\text { 27. Links to outside are appropriate. } \\
\text { 32. Headings are intuitive. } \\
\text { 34. Heading levels are appropriate to level of details. } \\
\text { 35. Structure of lists is consistent. } \\
\text { 36. Each paragraph has main idea. } \\
\text { 37. Presentation moves from general to specific. }\end{array}$ & $\begin{array}{l}\text { 38. Presentation moves from simple to complex. } \\
\text { 39. Presentation is limited to appropriate and necessary } \\
\text { topics. } \\
\text { 40. Presentation is in correct sequence. } \\
\text { Style and Text } \\
\text { 41. Style is consistent throughout the site. } \\
\text { 42. Paragraphs and sentences are used correctly. } \\
\text { 43. Present tense predominates. } \\
\text { 44. Readability level is acceptable. } \\
\text { 45. Text is simple, concise, and clear. } \\
\text { 46. New terms are highlighted and defined when first } \\
\text { used. } \\
\text { 47. First occurrences of abbreviations are followed } \\
\text { by spelled out words. } \\
\text { 48. Level of technical terms is appropriate to the } \\
\text { audience. } \\
\text { C. SUPPORTING USER TASKS } \\
\text { Interactive Tasks } \\
\text { 49. Reply forms are shorter than one page. } \\
\text { 50. Forms are easy to follow. } \\
\text { 51. Frequently Asked Questions (FAQ) is included. } \\
\text { 52. FAQ is provided at a task level. } \\
\text { 53. Help screens are included at a task level. } \\
\text { D. PRESENTING THE INFORMATION } \\
\text { Display and Download Speed } \\
\text { 54. Home page displays within no more than one } \\
\text { second. } \\
\text { 55. There is advance notice before downloading } \\
\text { large files. } \\
\text { 56. The pages display on an average sized screen. } \\
\text { 57. The pages work on different browsers. } \\
\text { Disability Access } \\
\text { 58. The page provides a text equivalent for every } \\
\text { non-text element. } \\
\text { 59. The page meets at least Bobby Priority } 1 \\
\text { standards for accessibility. } \\
\text { Navigation } \\
\text { 60. Clear Navigation tools are included. } \\
\text { 61. There is Navigation back to home page. } \\
\text { 62. There is Navigation up and down within a page. } \\
\text { Format } \\
\text { 63. Format is consistent throughout the site. } \\
\text { 64. Figures and tables are aligned correctly. } \\
\text { 65. White space is used effectively. } \\
\text { 66. Information is presented in readable blocks. } \\
\text { 67. Sentences are complete within web screen. } \\
\text { and }\end{array}$ \\
\hline
\end{tabular}




\section{Issues in Information Systems}

Volume 14, Issue 1, pp.189-196, 2013

68. Pages are printable with an average size paper.

A typical user will not spend time reading long passages of text on-screen; therefore, the long text needs to be divided into discrete chunks of information in a logical way using the hierarchy to structure relationships among chunks. This needs to be done carefully to make sure that content camouflage is avoided. This means that the message should not be buried deep in the hierarchy of a site's structure; rather it should be two clicks away [22]. Less critical information should be put at the bottom of the page and a text-only option needs to be offered for people who are using a slow network connection or are impatient [18].

As stated earlier, one of the objectives of this study was to determine whether there have been significant changes in university website design attributes within a decade $(2003$ - 2013). To this end, the result of this study was compared with that of 2003 [2]. T-test for independent samples was applied to determine significance in the differences between the ratings of 2013 and 2003. Table 2 shows the ratings for the subcategories of the website design attributes' survey, and the results of the t-test in terms of p-values. It is important to point out that the research study in 2003 involved a larger sample of university websites $(n=230)$ compared to the current study (2013), which has a significantly smaller sample size $(\mathrm{n}=72)$.

Table 2. Average Ratings for Subcategories Within a Decade

\begin{tabular}{|c|c|c|c|}
\hline Website Features' Subcategories & $\begin{array}{c}\mathbf{2 0 1 3} \\
(\mathbf{n = 7 2 )}\end{array}$ & $\begin{array}{c}\mathbf{2 0 0 3} \\
(\mathbf{n = 2 3 0})\end{array}$ & p-value \\
\hline Contents & 4.3 & 4.8 & .0022 \\
\hline Index & 4 & 3.4 & .0000 \\
\hline Site Map & 3 & 3.3 & .67 \\
\hline Headings & 5 & 4.4 & .0039 \\
\hline Search & 5 & 3.8 & .0000 \\
\hline Currency \& Accuracy of Information & 4 & 3.4 & .0000 \\
\hline Organization of site & 5 & 4.2 & .001 \\
\hline Style \& Text & 4.3 & 4.3 & .3000 \\
\hline Interactive Tasks & 3 & 3.5 & .55 \\
\hline Download Speed & 4.4 & 4.2 & .033 \\
\hline Disability Access & 3 & 3.4 & .656 \\
\hline Navigation & 4 & 4.1 & .0000 \\
\hline Format & 5 & 4.4 & .0123 \\
\hline
\end{tabular}

As presented in Table 2, universities have improved significantly in contents, index, headings, search, currency \& accuracy of information, site organization, navigation, and format. However, there have been no significant improvements in site map, style \& text, interactive tasks, download speed, or disability access of university websites. Interestingly, information contents subcategory is the only one that has shown significant lower ratings. However, in the current study the overall average rating for information content of the websites is 4.3 on the scale of $1-5$, which is indicative of effectiveness, although universities/colleges have room to improve.

According to the current study, shown in Table 2, the higher education institutions need to work on updating the information (rating of 4 for "Currency \& Accuracy of information" subcategory within the first major category of "FINDING THE INFORMATION"). However, as Table 3 shows, some attributes within the subcategory of "Currency and Accuracy of Information" are among the lowest rated website elements ( $2.7 \& 2.3$, and 2.9 out of 5). Among subcategories receiving a perfect rating of 5 are Headings, Search, Organization of site, and Format. 


\section{Issues in Information Systems}

Volume 14, Issue 1, pp.189-196, 2013

Another characteristic of a website is the navigation. A logical and successful website of an organization matches the users' expectations and will allow them to make predictions about where to find information. The designers should make visitors feel comfortable exploring the website $[6,12,16,27]$. Any factor that affects the ease of navigation, such as the manner information is arranged in the design, layout and sequencing, number and effectiveness of hyperlinks, and overall website organization, relates to the navigation characteristic [17, 21]. One of the difficulties that people have as they browse through a website is navigational problems, meaning they get lost within the structure. It's been shown in a study [3] that as many as $66.8 \%$ of users have trouble finding the information they need. In a good website design, the basic navigation links should be present consistently on every page in the same location. Measures of flexibility need to be embedded into a site to let visitors use their past experience from familiar pages for unfamiliar ones. Misleading website structures could result in frustrated users. The results of the current study (Table 2) show that the university websites need improvement in Navigation (rating of 4 out of 5 ).

Table 3. Lowest rated website attributes

\begin{tabular}{|lc|}
\hline Website attributes & Average Rating \\
\hline The date of the last updated is included & 2.7 \\
The last updated date is on every page & 2.3 \\
The new information is indicated & 2.9 \\
\end{tabular}

Usability is another website characteristic that relates to the ease of use. Experts agree that the website design should make it fun and visually attractive to the visitors. Flexibility and interesting features such as search engine and graphics can make the experience easier and enjoyable for viewers $[1,13]$. The search facility of the university websites involved in this study received excellent ratings from the students. Technical properties of websites include provisions such as security and overall technical reliability of the website. By definition, the website capability that allows user authentication is called security $[14,26]$. The overall technical reliability, which depends on the underlying IS infrastructural platform, defines the access speed (how fast the website's pages are downloaded and displayed) and the accessibility and availability of the website. The results of this research indicate that universities have managed to design their websites so that the access speed is not compromised. The average rating of 4.4 for downloading pages and moving from one page to another shows this fact.

\section{CONCLUSIONS}

In today's competitive market it is crucial that higher education institutions explore every avenue for recruiting new students. Today's media-savvy students have adapted to the current media-saturated environment by learning how to scan through massive amounts of information quickly and locate the desired information. Universities and colleges have begun to use their websites as a recruiting tool [23]. Therefore, higher education institutions need to address the needs of their target audience and design effective websites to attract students.

This study attempted to shed some light on the university websites' situation. Seventy-two randomly selected universities were involved in this research investigation. The website design's attributes identified in the literature [19] were used to assess the effectiveness of university websites from students' perspectives. The results were analyzed to show the overall weaknesses and strengths of the university websites involved in the study. The 


\section{Issues in Information Systems \\ Volume 14, Issue 1, pp.189-196, 2013}

findings show that the universities have succeeded in presenting a high range of information that is relevant and applicable to their website. However, they need to improve on updating their information and presenting it in a layout that will make it easier for users to locate the information of interest. Also, they have been careful about the download speed since the results indicate that pages can be downloaded at a good speed. However, the universities need to improve in the areas of disability access, interactive tasks, and site map. The websites' navigational components received an overall average rating of 4, which indicates effectiveness of the website, however, there's room for improvement. The organization of the site and style and text of these websites, that is the attractiveness, getting the user excited about the website, ease of use, and having attractive layout were rated high (5 and 4.3 respectively).

Finally, it needs to be emphasized that the sample selected for this study was the 72 universities in the country. However, larger sample would be recommended. The hope is that ultimately colleges and universities can improve their web sites and increase recruitment of prospective students. Further research needs to be done to help universities to achieve this objective.

\section{REFERENCES}

1. Agarwal, R. and Venkatesh, V. (2002). Assessing a Firm's Web Presence: A Heuristic Evaluation Procedure for the Measurement of Usability. Information Systems Research, V. 13, (2), pp. 168-186.

2. Astani, Marzie. (2003). An Empirical Study of the Effectiveness of Universities' websites. Issues in Information Systems. V. IV, (1), pp. 14-20.

3. Bernard, Michael. (2002). Criteria for Optimal Web Design. Software Usability Research Laboratory, http://psychology.wichita.edu/optimalweb/structure.html, (accessed February 6, 2013).

4. Bruce, H. (1998). User Satisfaction With Information Seeking on the Internet. Journal of the American Society of Information Sciences. V. 49, (6), pp. 541-556.

5. Cappel, J. and Huang, Z. (2007). A Usability Analysis of Company Websites. Journal of Computer Information Systems. V. XLVIII, (1), pp. 117-123.

6. Ceaparu, I and Shneiderman, B. Improving Web-based Civic Information Access: A Case Study of the 50 U.S. States. ftp://ftp.cs.umd.edu/pub/hcil/Reports-Abstracts-ibligraphy/2002-12html2002-12.pdf, (accessed February 6, 2013).

7. Chen, P. and Hitt, L.M. (2002). Measuring Switching Costs and the Determinents of Customer Retention in Internet-Enabled Businesses: A study of the Online Brokrage Industry. Information Systems Research. V. 13, (3), pp. 255-274.

8. Dewan, R. Freimer, M. and Zhang, J. (2002). Management and Valuation of Advertisement-Supported Web Dites. Journal of Management Information Systems. V. 19, No 3, pp. 87-98.

9. Greer, T.H. and Murtaza, M.M. (2003). Web Personalization: The Impact of Perceived Innovation Characteristics on the Intention to Use Personalization. Journal of Computer Information Systems. V. XLIV, (3), pp. 50-53.

10. Kaplan S. and Kaplan, R. (1982). Cognition and environment. New York, NY: Preager Publishers, pp. 5-6.

11. Katterattanukul, P. and Siau, K. (1999). Measuring Information Quality of Web Sites: Development of an Instrument. Proceedings of the $20^{\text {th }}$ International Conference on Information Systems. Pp. 279-285.

12. Lynch, P. and Horton, S. (March 2002). Web Style Guide: Basic Design Principles for Creating Web Sites, Second Edition. Yale University Press.

13. McKinney, V.; Yoon, K. and Zahedi, F. (2002). The Measurement of Web-Customer Satisfaction: An Expectation and Disconfirmation Approach. Information Systems Research. V. 13, (3), pp. 296-315.

14. McKnight, D.H., Choudhury, V. and Kacmar, C. (2002). Developing and Validating Trust Measures for eCommerce: An Integrative Typology. Information Systems Research. V. 13, (3), pp. 334-359.

15. Newman M. et al. (2000). Carnegie Mellon University Research Showcase. http://repository.cmu.edu/hcii, (accessed April 17, 2013).

16. Nielsen, J. (May 1999). "Top Ten Mistakes" Revisited Three Years Later. Nielsen's Alertbox,. http://www.useit.com/alertbox/990502.html, (accessed February 20, 2013).

17. Nielson, J. (2000). Designing Web Usability. Indianapolis, IN. New Riders. 


\section{Issues in Information Systems \\ Volume 14, Issue 1, pp.189-196, 2013}

18. Pretzer, Mary. (1998). Common Sense Web Page Design: Cleaning Out the COB Webs. Rural Telecommunications, Vol. 17, (4).

19. Raward, Roslyn. (2001). Academic Library Website Design Principles: Development of a Checklist. Australian Academic \& Research Libraries, V32, i2, p.123-134.

20. Rosen D. \& Purinton, E. (2004). Website design: Viewing the web as a cognitive landscape. Journal of Business Research, 57 pp. 787-794, 2004.

21. Shchiglik, C. and Barns, S.J. (2004). Evaluating Website Quality in the Airline Industry. Journal of Computer Information Systems. V. XLIV, (3), pp. 17-25.

22. Showker, Fred. (1998). Removing Barriers. Electronic Publishing, V. 22, (5).

23. Steele, Jonathan. (2002). The Media Omnivores: Understanding College-bound Students and Communicating with Them Effectively. NACAC Journal of College Admission, (175). http://www.dehne.com/news_research/research_media_omnivores. (accessed February 6, 2013).

24. Tarafdar, M. and Zhang, J. (2005-2006). Analysis of Critical Website Characteristics: A Cross-Category Study of Successful Websites. Journal of Computer Information Systems. V. XLVI, (2), pp. 14-24.

25. Tarafdar, M. and Zhang, J. (2007-2008). Determinants of Reach And Loyalty - A Study of Website Performance And Implications For Website Design. Journal of Computer Information Systems. V. XLVIII, (2), pp. 16-24.

26. Torkzadeh, G. and Dhillon, G. (2002). Measuring Factors that Influence the Success of Internet Commerce. Information Systems Journal. V. 13, (2), pp. 187-204.

27. Weinstein, Peter. (1997). Tips and tools for building a school Website. Technology \& Learning. V. 17, (4), p 25-37.

28. Van Schaik, and Ling, J. (2007). Design Parameters of Scales For Web Sites. ACM Transactions on Computer-Human Interaction. V. 14, (1), pp. 1-35.

29. Yeung, W. and Lu, M. (2004). Gaining Competitive Advantages Through A Functionality Grid For Website Evaluation. Journal of Computer Information Systems. V. XLIV, (4), pp. 67-77. 